\title{
A Rare Case of Parathyroid Adenoma Presenting As Acute Pancreatitis
}

\author{
Dr. Korumilli Ramesh Kumar ${ }^{1}$, Dr. A. Sai Datta ${ }^{2}$, Dr. G. Gautham Reddy ${ }^{3}$ \\ ${ }^{\prime}$ (professor of general surgery, svs medical college/Dr.NTR University of Health Sciences, India) \\ ${ }^{2}$ (associate prof. of general surgery, katuri medical colleg/Dr.NTR University of Health Sciences, India) \\ ${ }^{3}$ (assistant prof. of general surgery, svs medical college/Dr.NTR University of Health Sciences, India)
}

\begin{abstract}
Acute pancreatitis as a first manifestation of primary hyperparathyroidism (PHPT) caused by parathyroid adenoma is exceptionally rare. A 24 year old female presented with pain in the left side of chest, upper abdomen and breathlessness. Laboratory studies showed elevated levels of calcium, amylase, lipase and parathormone. She was found to have associated gall stones, pancreatic and renal medullary calcifications and also left sided pleural effusion. Tc $99 \mathrm{~m}$ scan showed increased activity of right inferior parathyroid gland. The patient underwent surgical resection of the functioning parathyroid adenoma. Although the actual causal relationship between hypercalcemia and pancreatitis has been a persistent topic of debate, detection of hypercalcemia may be a clue to diagnose PHPT due to parathyroid adenoma.
\end{abstract}

Keywords: Acute pancreatitis, Hypercalcemia, Parathyroid adenoma, Tc 99 m sestamibi scan.

\section{Introduction}

Acute pancreatitis secondary to hypercalcemia is an uncommon presentation of primary hyperparathyroidism (PHPT) and its prevalence is estimated to be between $1.5 \%$ and $7 \%{ }^{[1]}$. Acute pancreatitis as the first manifestation of PHPT caused by a parathyroid adenoma is exceptionally rare. The metabolic causes of acute pancreatitis include diabetic ketoacidosis, hypertriglyceridemia, and hypercalcemia with or without hyperparathyroidism ${ }^{[2]}$. PHPT is most commonly caused by parathyroid adenoma and rarely by parathyroid carcinoma or parathyroid cyst ${ }^{[3]}$.

\section{Case Report}

A 24 year old female presented with upper abdominal pain, fever and breathlessness of two weeks duration. Pain was radiating to back and getting relieved on stooping forward posture. No history of alcohol intake. The clinical picture was suggestive of acute pancreatitis. Investigations revealed the following results: serum amylase was $422 \mathrm{IU} / \mathrm{L}$, serum lipase was $612 \mathrm{IU} / \mathrm{L}$, serum calcium was $14.2 \mathrm{mg} / \mathrm{dl}$, parathormone level was $344.67 \mathrm{pg} / \mathrm{ml}$, serum phosphorus was normal. X-ray chest showed left sided pleural effusion. X-ray abdomen showed calcifications in pancreas and renal and gall stones. Ultrasound abdomen confirmed the $\mathrm{x}$-ray findings and showed $4.8 \times 10.4 \mathrm{~cm}$ size pseudocyst in the pancreas. Tc $99 \mathrm{~m}$ sestamibi $740 \mathrm{Mbq}$ scan showed right inferior parathyroid adenoma(Fig.1)

\section{A rare case of parathyroid adenoma presenting as acute pancreatitis}

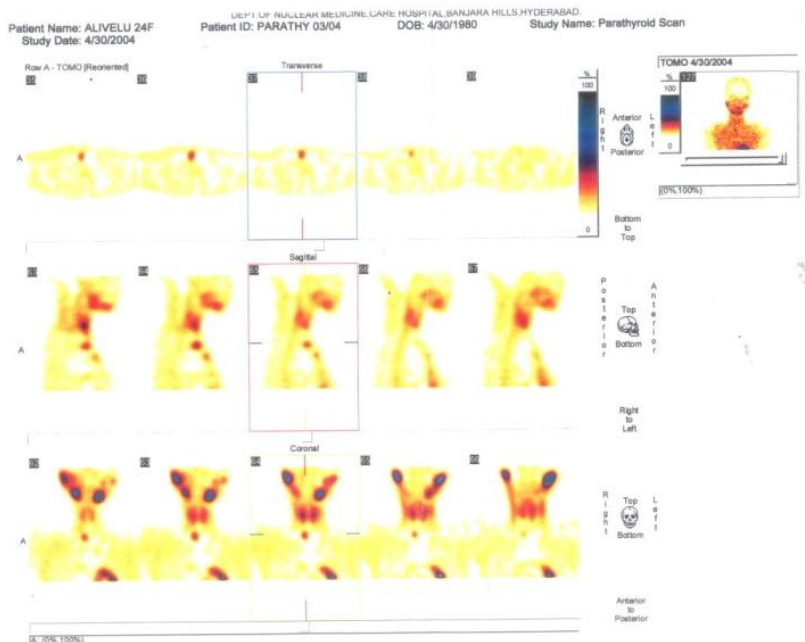

Fig.1 Tc 99 m sestamibi scan showing increased activity in right inferior parathyroid adenoma. 
After initial management, surgery was planned. Exploration of the neck was done and right inferior parathyroid adenoma was excised(Fig.2).Laparotomy with external drainage of infected pseudocyst was done. Histopathological report was consistent with parathyroid adenoma(Fig.3).

\section{A rare case of parathyroid adenoma presenting as acute pancreatitis}

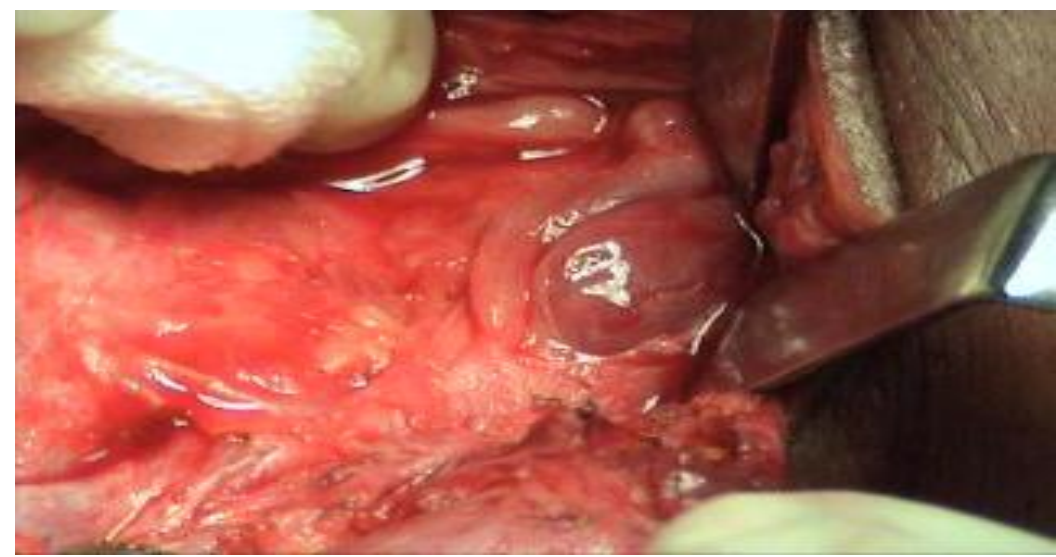

Fig.2 Operative photograph showing right inferior parathyroid adenoma

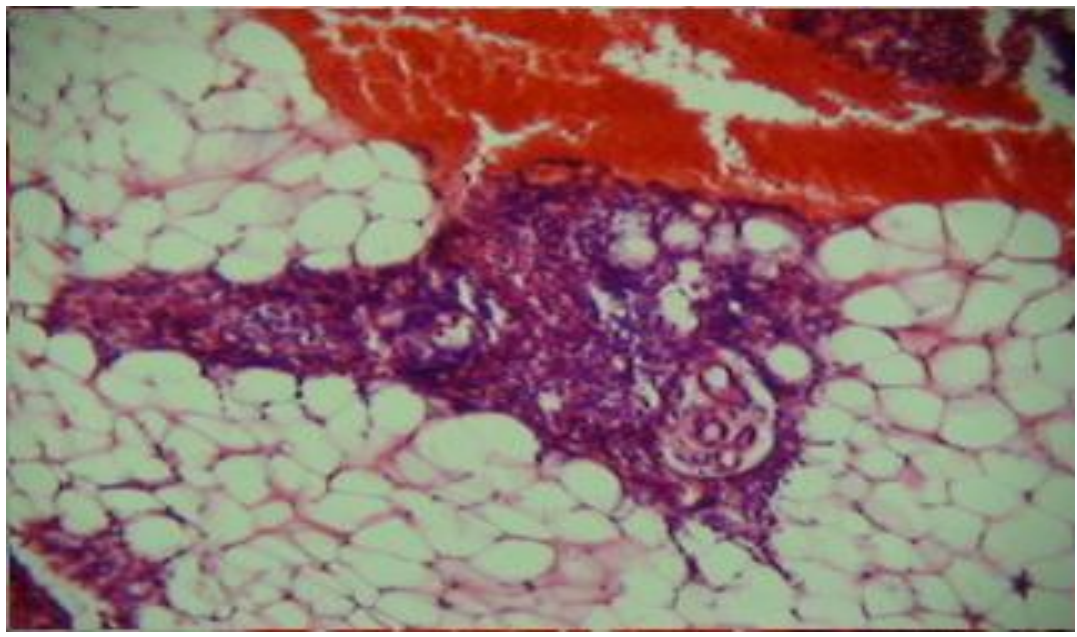

Fig.3 Histopathology showing parathyroid adenoma

A rare case of parathyroid adenoma presenting as acute pancreatitis

Post-operative period was uneventful. Follow-up after one month showed normalised levels of amylase, lipase, calcium and parathormone. No recurrent episodes of abdominal pain and breathlessness. One year later also she was asymptomatic.

\section{Ш. Discussion}

Many conditions predispose to acute pancreatitis to varying degrees. These conditions include gallstones, alcohol, hypertriglyceridemia, and hyperglycemia ${ }^{[2]}$. Any cause of hypercalcemia, including hyperparathyroidism, metastatic bone disease, total parenteral nutrition, sarcoidosis, vitamin D toxicity, and infusions of calcium, can lead to acute pancreatitis ${ }^{[4]}$.

Hypercalcemia is one of the rare causes of acute pancreatitis and ectopic activation of trypsinogen to trypsin by hypercalcemia ${ }^{[5]}$, hypercalcemia induced formation of pancreatic calculus ${ }^{[6]}$ and genetic defects in SPINK 1 (serine protease inhibitor Kazal Type 1) and CFTR (cystic fibrosis transmembrane conductance regulator) genes ${ }^{[7]}$ have been suggested as possible mechanisms of acute pancreatitis in the setting of hypercalcemia. Hypocalcemia is a poor prognostic factor in acute pancreatitis ${ }^{[8]}$. However, when hypercalcemia is detected in acute pancreaititis it should compel clinicians to search for alternative explanations such as malignancy or hyperparathyroidism. In this case the presence of hypercalcemia in acute pancreatitis guided us to detect undiagnosed PHPT and a parathyroid adenoma. clinical improvement after parathyroidectomy supports a likely relationship between PHPT and acute pancreatitis in this case. 


\section{IṼ. Conclusion}

Although the actual causal relationship between hypercalcemia and pancreatitis has been a persistent topic of debate, detection of hypercalcemia may be a clue to diagnose PHPT due to parathyroid adenoma. After aggressive medical management of acute pancreatitis parathyroidectomy may improve clinical outcome and prevent further recurrences of pancreatitis.

\section{References}

[1]. Egea Valenzuela J, Belchí Segura E, Sánchez Torres A, Carballo Alvarez F. Acute pancreatitis associated with hypercalcemia. A report of two cases. Rev Esp Enferm Dig 2009;101:65-69.

[2]. Bai HX, Giefer M, Patel M, Orabi AI, Husain SZ. The association of primary hyperparathyroidism with pancreatitis. J Clin Gastroenterol 2012;46:656-661.

[3]. Fraser WD. Hyperparathyroidism. Lancet 2009;374:145-158

[4]. Frick TW. The role of calcium in acute pancreatitis. Surgery 2012;152 3 Suppl 1:S157-S163.

[5]. Frick TW, Fernandez-del Castillo C, Bimmler D, Warshaw AL. Elevated calcium and activation of trypsinogen in rat pancreatic acini. Gut. 1997;41(3):339-343

[6]. Cope O, Culver PJ, Mixter CG, Jr., Nardi GL. Pancreatitis, a diagnostic clue to hyperparathyroidism. Ann Surg. 1957;145(6):857863 .

[7]. Felderbauer P, Karakas E, Fendrich V, Bulut K, Horn T, Lebert R, Holland-Letz T, et al. Pancreatitis risk in primary hyperparathyroidism: relation to mutations in the SPINK1 trypsin inhibitor (N34S) and the cystic fibrosis gene. Am J Gastroenterol. 2008;103(2):368-374.

[8]. Ranson JH. Etiological and prognostic factors in human acute pancreatitis: a review. Am J Gastroenterol. 1982;77(9):633-638. 